\title{
Integration of LEAN Last Planner System in construction processes
}

\author{
Jolanta Tamošaitienë* Tomas Starta \\ Department of Construction Management and Real Estate, Faculty of Civil Engineering, \\ Vilnius Gediminas Technical University, Vilnius, Lithuania
}

\begin{abstract}
Globally, the efficiency of the construction sector has declined around the world over the past 30 years. The main principles aimed at the improvement of the situation are based on lean construction. The concept of lean construction can be effectively used in the strategic process to improve waste reduction as well as cost and time efficiency, which results in positive outcomes such as environmental protection, economy and time-saving. Lean construction practices help to achieve significant benefits. However, many organisations still find it difficult to successfully and correctly integrate lean concepts. The research literature indicates that the construction industry has encountered poor implementation and integration of these concepts. Lean construction has eight main techniques for increasing productivity in implementing customer requirements in the construction industry. Having in mind that lean is the key requirement for gaining construction productivity, this paper provides the basic fundamental knowledge of lean construction. Also, it shows how to get the most effective results by applying the Last Planner System technique. The described case study demonstrates the integration of the Last Planner System technique into the project.
\end{abstract}

Keywords: lean, the Last Planner System, construction, time saving.

\section{Introduction}

Lean is a better way to build and create an all-encompassing process and culture system based on a commitment to collaborate and share knowledge. Lean ensures better employee retention and quality of life as well as safer and more comfortable jobs. Also, it reduces project waste and increases project value. The lean technique must be used to achieve the greatest lean potential. In this case study, the Last Planner System technique was applied. The Last Planner System promotes communication between all stakeholders at the right level, which helps to solve problems before they arise. The communication increases the likelihood of honest and effective work as well as recognises that personal relationships and peer pressure are crucial to this process. In this paper, the Last Planner System was adapted to a construction management group and for the optimisation of the construction processes.

\section{Literature review}

Lean construction is a customised general principle that originated from the Japanese manufacturing industry. The lean concept has been applied and implemented in the construction process as a factor enhancing efficiency and rationality (Bertelsen, 2004). Under conditions of a changing economy, the modern construction sector is becoming increasingly more interested in lean construction. The scientific literature has many definitions and perceptions of lean construction. The most important issue in lean construction is the development aimed at improving industrial culture, organisational and managerial styles, attitudes, roles, relationships, actions and communication among project participants to overcome obstacles (Koskela, 1998; Sarhan \& Fox, 2013a; Egan, 1998). Lean construction is similar to the current practice aimed at the increase of customer satisfaction and business performance (Bertelsen, 2004). The main goal is to reduce the amount of waste as well as improve and maintain a new production philosophy (Green \& May, 2005). Lean construction offers the concept and understanding of wasted resources in projects managed using traditional approaches and facing different experiences and difficulties in controlling results (Howell \& Ballard, 1998). Typically, in traditional construction, the main goal is to optimise one part of the process, while lean construction makes optimisations at the project level, which requires different experience, practice and work management (Murman et al., 2002). Concepts of lean production or manufacturing production involve a variety of production systems that share certain principles, including waste reduction, response to change, just-in-time, effective value-to-stream, continuous improvement and quality from the outset (Johansen \& Walter, 2007). Based on the position of a committee of the

\footnotetext{
${ }^{*}$ Corresponding author. E-mail: jolanta.tamosaitiene@vgtu.lt
}

(C) 2019 Authors. Published by VGTU Press. This is an open-access article distributed under the terms of the Creative Commons Attribution (http://creativecommons.org/licenses/by/4.0/) License, which permits unrestricted use, distribution, and reproduction in any medium, provided the original author and source are credited. 
Construction Industry Institute, the implementation of lean principles begins with leadership responsibilities and a culture of continuous improvement. Properly applied principles at the project level can achieve a significant improvement in safety, quality and efficiency results. Process and enterprise-level improvements are more conducive to enhancing a project at different levels and ensuring the sustainability of such refinements (Construction Industry Institute, 2007).

While many companies have recruited skilled professionals knowledgeable in building processes and aware of changes and improvements in the industry, there are still problems that prevent the implementation of the lean philosophy. The literature is clear that the application of the lean principle or tool would be insufficient without a consistent lean culture (Sarhan \& Fox, 2013b). To deliver value to customers, it is very important to have a broad approach to the lean concept in a balanced way throughout the system focusing on key characteristics, namely, personal attention, collaboration and motivation (Hook \& Stehn, 2008).

A systematic review of the literature on previous empirical studies is presented in Table 1, which discusses lean construction. The table specifies theoretical foundations, their principles and the respective literature sources (Marhani, Jaapar, \& Bari, 2012).

Table 1. Lean Construction Concept

\begin{tabular}{|l|l|}
\hline \multicolumn{1}{|c|}{ Theoretical foundations } & \multicolumn{1}{c|}{ Principles } \\
\hline $\begin{array}{l}\text { Revolution in the } \\
\text { production environment } \\
\text { and meeting customer } \\
\text { needs }\end{array}$ & $\begin{array}{l}\text { LC was developed as a production management method for project presentation: a new method for } \\
\text { designing and building capital instruments; a new production philosophy to increase value, reduce } \\
\text { waste and resources to maximise customer value (Womack \& Daniel, 1996; Picchi \& Granja, 2004) }\end{array}$ \\
\hline $\begin{array}{l}\text { Balanced resource } \\
\text { allocation }\end{array}$ & $\begin{array}{l}\text { Balanced use of people, materials and resources; reduced costs, waste disposal and timely delivery } \\
\text { of projects (Paez, Solomon, Salem, \& Genaidy, 2005) }\end{array}$ \\
\hline
\end{tabular}

\section{Customised Last Planner System}

One of the best-known lean methods is the Last Planner System, which has been proven to be a very useful tool for managing the construction process and for continuous monitoring of planning efficiency, helping to develop forecasts, mitigate workflow variations and reduce/eliminate uncertainties in construction processes. It consists of workflow control and production unit management. Workflow control is primarily a review process, and production unit control is performed primarily through weekly work planning (Marhani et al., 2012). Constraint analysis is an integral part of the Last Planner System that is applied as a proactive approach to problem-solving as a team, despite the typical challenges faced by construction projects.

The Last Planner System is a simple process that allows a team to create and maintain a reliable workflow in construction projects. To apply the Last Planner System, eight key factors must be adopted to ensure the effectiveness of the system.

The first part is the master planning. In this part, the team must be in alignment with a mark in the Master Schedule. This section mainly focuses on familiarising all team members with the current project plan and indicating parts of the team responsible for particular parts of the project in the plan. In this case study, the project implementation team had one project manager and three construction managers. So, in the first stage, the project manager appointed a responsible construction manager for each part of the project. Column 3 of Figure 1 lists people responsible for each part.

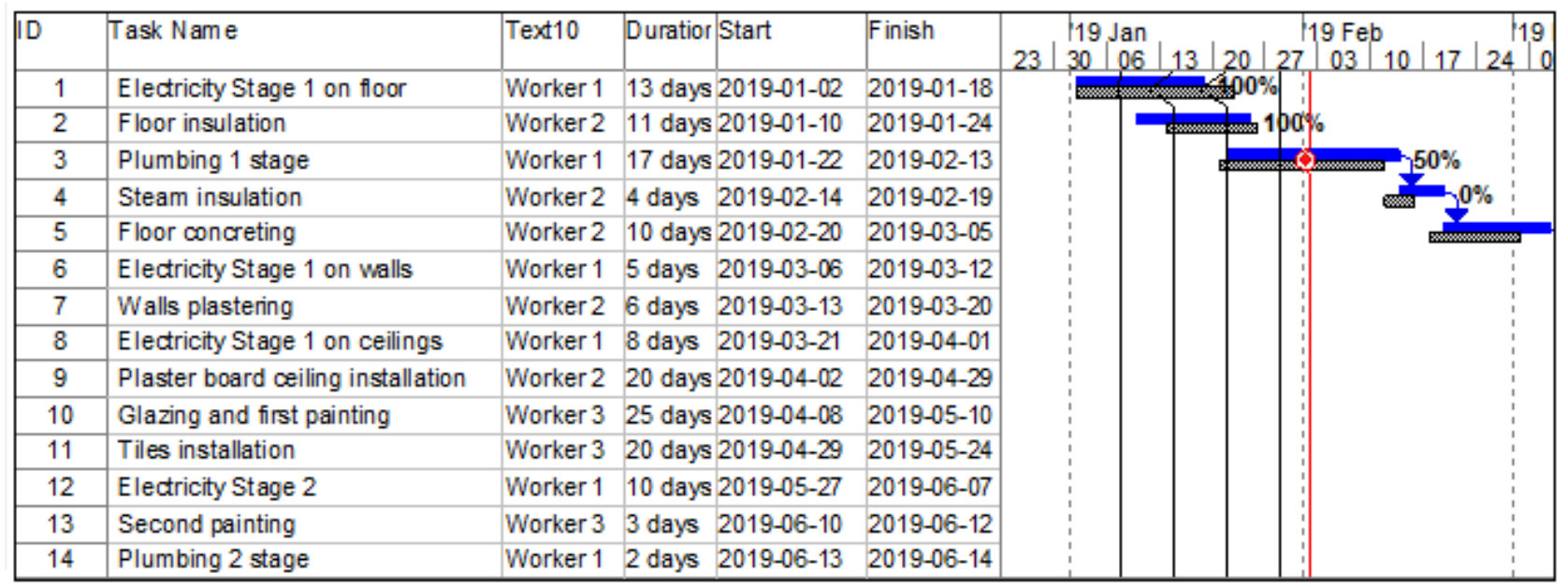

Figure 1. Schedule chart 
The second part is the pull planning. Strategically important work segments are used for the gradual development of daily work plans. Four columns are used to represent different categories of tasks, i.e., "to do", "doing", "done" and "pending"; also, colour coding is used. Pull planning helps to understand what exactly has been done, is being done and will be done, allowing to draw conclusions regarding the efficiency, rationality and productivity of each employee well as helping to control the work of managers.

The third part in the adaptation of the Last Planner System is the development of a ready plan. In this part, to gradually prepare the planning process, it is very important to develop a plan and to eliminate as many problems as possible. The main idea of this part is to understand, what can happen during the input into the process and what will happen during the output. In this case study, after the development of the look-ahead schedule and analysis, two constraints were found that could impede on the implementation of the project. Lines 5 and 11 of Figure 1 , show problems that were identified. Line 5 demonstrates that the actual concrete floor casting will take longer than contractually scheduled. As a result, the decision was made to divide the volume of work into two parts and to hire an additional subcontractor to perform the works in parallel (Figure 2). These methods not only eliminate the risk of delays but also ensure that the work is done faster than foreseen in the contractual schedule, increasing the time reserve and helping to manage the risk of delays. Line Y shows that no subcontractors were provided for window installation. As a result, the project manager assigned to the construction manager to find a window fitting subcontractor. Ultimately, this will prevent unscheduled product orders and unexpected downtime.

During the "ready planning" part, the length of the construction process can be reduced, avoiding unplanned delays in construction work as well as unscheduled material orders. A time reserve can be built to help in the management of construction risk. For these reasons, it is very important for a project manager and all construction managers to devise a look-ahead schedule and analyse the process every week.
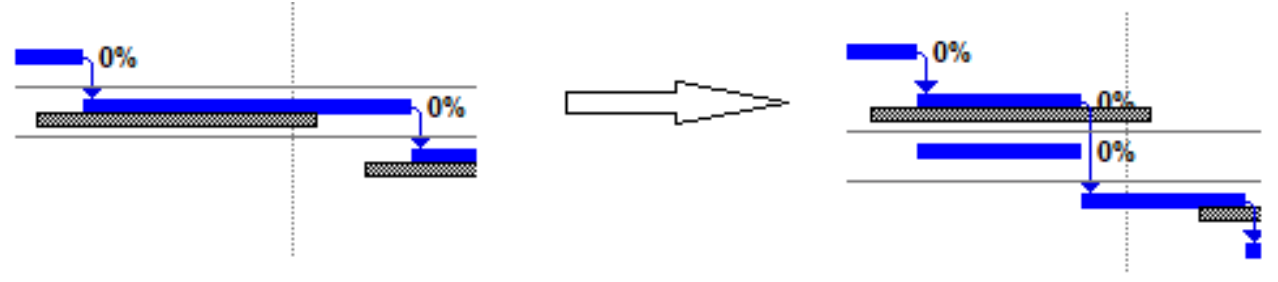

Figure 2. Schedule optimisation

Part four is weekly work planning. This step requires the creation of a tactical team that collaborates in the planning of each day, anticipating the related conditions, sequencing and synchronising the next week's work. The main focus of such gradual development is to design reliable work plans.

Part five focuses on daily huddles. In this part, the project team (which in this case study is comprised of one project manager and three construction managers) discusses the weekly work plan. The main idea of this part is to understand how everything is going, whether the schedule is implemented according to plan, and what can be changed to get a better result. In this case study, "plumbing 1 stage" was lagging behind the schedule by two days. As a result, the decision was made to increase the production capacity, so that the work would be done on time as stipulated in the contractual schedule.

Part six requires to develop the plan demonstrating the stage of the project completion. This step aims to understand the efficiency of each employee. The efficiency is the result of the total number of completed activities divided by the total number of planned activities. This helps to determine the efficiency of the entire group of employees for each week and the percentage of achievement of the set goals.

The seventh part is linked to the sixth part and focuses on finding the reason for the variance. The trend line shows the variance coefficient. Aiming to improve the overall percentage value of the next week's plan, it is very important to know what needs to be fixed. In this case study, the first and second weeks had the execution rate of about $80 \%$. According to the LPS theory, such an execution rate is appropriate; therefore, the work was being carried out rationally and efficiently. However, it should be noted that in the third week, the execution rate fell to $67 \%$. Such a deviation from the positive result was caused by internal company problems. Rapid response to the situation and resolution of the problems produced a positive result in the fourth and fifth weeks.

The final part of the Last Planner System is team health, maturity and efficiency, which form the essence of collaboration. This step requires to understand everything that has been done the right way, lessons learnt, issues that require attention and the remaining challenges as well as the kind of help the team needs to be successful. Team members should be able to speak openly about strengths and weaknesses without fear of reprisal.

\section{Conclusions}

To effectively implement a successful lean planning system, practitioners and early users must be disciplined and apply balanced efforts to all eight key elements. In each case, it is important to learn from variance and always collaborate on 
improving the behaviour and interaction between the people in the system. This paper applied the Last Planner System to achieve the following results: in the 1st part, a construction manager responsible for each project part was selected; in the 2nd part, the work was organised and the understanding was gained of what exactly workers have done, were doing and would do; in the 3rd part, the length of the construction process was reduced by avoiding unplanned delays in construction work as well as unscheduled material orders, which helped to build a time reserve and manage construction risks; in the 4th part, reliable work plans were developed; in the 5th part, the production capacity was increased and the work was finished on time as stipulated in the contractual schedule; in the 6th part, the efficiency of the workgroup was obtained; in the 7th part, the percentage of efficiency was brought back to the appropriate level; in the 8th part, team members talked openly about strengths and weaknesses without fear of reprisal. In can be stated that all of these parts of the Last Planner System resulted in the lean project and allowed reaching the best result.

\section{References}

Bertelsen, S. (2004). Lean construction: Where are we and how to proceed. Retrieved from http://www.kth.se

Bertelsen, S. (2004). Lean construction: Where are we and how to proceed? In Proceedings of the $12^{\text {th }}$ Annual Conference in the International Group for Lean Construction, 3-5 August 2004 (pp. 46-69). Elsinore, Denmark.

Construction Industry Institute (CII). (2007). Lean implementation at the Project level (Research summary). The University of Texas at Austin, 234-1, 1-36.

Egan, J. (1998). Rethinking construction: Report of the construction task force. London: HMSO.

Green, S., \& May, S. (2005). Lean construction: arenas of enactment, models of diffusion, and the meaning 'leanness'. Building Research \& Information, 33(6), 498-511. https://doi.org/10.1080/09613210500285106

Hook, M., \& Stehn, L. (2008). Applicability of lean principles and practices in industrialised housing production. Construction Management and Economics, 26(10), 1091-1100. https://doi.org/10.1080/01446190802422179

Howell, G. A., \& Ballard, G. (1998). Implementing lean construction: Understanding and action. In Proceedings of the $6^{\text {th }}$ Annual Conference of the International Group for Lean Construction, International Group for Lean Construction (IGLC), 13-15 August 1998 (pp. 1-9). Guaruja, Brazil.

Johansen, E., \& Walter, L. (2007). Lean construction: Prospects for the German construction industry. Lean Construction Journal, $3(1), 19-32$.

Koskela, L. (1998). Lean construction. VII Encontro Nacional de Technologia do Ambiente Construido. 1998, Abril 27-30, Florianópolis. Anais, vol. 1, 3-10.

Marhani, M. A., Jaapar, A., \& Bari, N. A. A. (2012). Lean Construction: Towards enhancing sustainable construction in Malaysia. Procedia - Social and Behavioral Sciences, 68, 87-98. https://doi.org/10.1016/j.sbspro.2012.12.209

Murman, E., Allen, T., Bozdogan, K., Cutcher, J. G., McManus, H., Nightingale, D., Rebentisch, E., Shields, T., Stahl, F., Walton, M., Warmkessel, J., Weiss, S., \& Widnall, S. (2002). Lean enterprise value: Insight from MIT's lean aerospace initiative. Palgrave, New York. https://doi.org/10.1057/9781403907509

Paez, O., Salem, S., Solomon, J., \& Genaidy, A. (2005). Moving from lean manufacturing to lean construction: Toward a common sociotechnological framework. Human Factors and Ergonomics Manufacturing Journal, 15(2), $233-245$. https://doi.org/10.1002/hfm.20023

Picchi, F., \& Granja, A. (2004). Construction site: using lean principles to seek broader implementation. In $12^{\text {th }}$ International Group of Lean Construction Annual Meeting (vol. 1, 1-1). Elsinore.

Sarhan, S., \& Fox, A. (2013a). Performance measurement in the UK construction industry and its role in supporting the application of lean. Australasian Journal of Construction Economics and Building, 13(1), 23-35. https://doi.org/10.5130/AJCEB.v13i1.3069

Sarhan, S., \& Fox, A. (2013b). Barriers to Implementing Lean Construction in the UK Construction Industry. The Built \& Human Environment Review, 6, 1-17.

Womack, J. P., \& Daniel, T. J. (1996). Lean thinking. New York: Simon and Schuster, 350. 